\title{
Jornalismo e conhecimento da realidade objetiva no século XX|1
}

\section{Journalism and knowledge of objective reality in the 21st century}

Rafael Bellan Rodrigues de Souza ${ }^{2}$

Resumo: O artigo explora a questão do conhecimento da realidade objetiva pelo jornalismo. Cotejando a perda de sentido do real expresso tanto na hegemonia irracionalista do território digital, quanto em importantes correntes de pensamento hegemônico de estudos do jornalismo, o texto aponta a práxis noticiosa como forma de conhecimento imersa em uma sociedade de classes, avaliando a sua potência na busca da concreticidade. Para isso, assume a perspectiva da ontologia do ser social em Marx para debater a possibilidade de conhecimento da objetividade, investigando as peculiaridades do jornalismo no edifício conceitual da dialética materialista. Assim, apresenta uma caracterização ontológica crítica para um dos problemas centrais do jornalismo no contexto do capitalismo digital do século XXI.

Palavras-chave: Teorias do jornalismo; realidade objetiva; conhecimento; marxismo.

\footnotetext{
Abstract: The article explores the question of the knowledge of objective reality by journalism. Comparing the loss of meaning of the real expressed both in irrationalist hegemony in the digital territory and in important hegemonic thought currents of journalism studies, the text points to news praxis as a form of knowledge immersed in a class society, evaluating its power in pursuit of concreteness. For this, it takes the perspective of the ontology of social being in Marx to

1 Versão revista e ampliada de trabalho apresentado no $17^{\circ}$ Encontro Nacional de Pesquisadores em Jornalismo (SBPJor), realizado em Goiânia - GO, em novembro de 2019.

2 Universidade Federal do Espírito Santo (UFES). Vitória, ES, Brasil.

https://orcid.org/0000-0003-0165-2927. E-mail: rafaelbellan@yahoo.com.br
} 
debate the possibility of knowledge of objectivity, investigating the peculiarities of journalism in the conceptual building of materialist dialectic. Thus, it presents a critical ontological characterization for one of the central problems of journalism in the context of 21 st century digital capitalism.

Keywords: Theories of Journalism; Objective reality; Knowledge; Marxism. 


\section{Introdução}

Há um profundo mal-estar nas avaliações científicas sobre os rumos do território digital comunicacional e o papel do jornalismo nessa esfera. Anteriormente visto por tecnoutopistas da estatura de um Castells (2007) como a expressão mais bem acabada da democratização total da informação e do conhecimento, recentemente autores como Morozov (2018), Fuchs (2016), Dean (2010), Moretzsohn (2017), entre outros, apontam o quanto essas plataformas on-line têm se direcionado pelos mantras fetichistas do capital e dado vazão ao irracionalismo, cuja expressão formal no jornalismo evidencia-se limpidamente no fenômeno das "fake news". Esse processo de combate à expressão da razão crítica tem sido elaborado por correntes pós-modernistas (EAGLETON, 1996) que, enfim, alcançaram o senso comum por meio da força turbinada das mídias sociais. Nesse pensamento hegemônico, como aponta Netto (2010), a ideia de verdade é transformada em artefactualidade discursiva, um consenso intersubjetivo, e é negada a existência de uma realidade existente independente da consciência. É como se os significantes rodassem em falso sem os referentes materiais. A reificação intensificada no capitalismo comunicacional (DEAN, 2010) produz no campo do pensamento e do senso comum a percepção de fim da possibilidade de conhecimento, agora substituído por crenças e narrativas ficcionais sobre o próprio real. Há nas últimas décadas uma intensificação dos elementos irracionais da decadência ideológica (LUKÁCS, 2016) em cenário de cooperação complexa (FREDERICO; TEIXEIRA, 2008) do capital no século XXI.

Embora a plataforma digital em que o jornalismo tem se espraiado nas últimas décadas tenha possibilitado sua ampla disseminação, a gramática irracionalista de busca por resultados rápidos da economia da atenção, construída pelas redes sociais, também se tornou câmara de eco das notícias falsas, fenômeno nada atual, mas nunca antes tão efetivo na constituição do metabolismo do capital. Por outro lado, vertentes neopositivistas (principal corrente inspiradora dos salvacionistas autointitulados checadores de fatos) também coisificam o real, não 
compreendendo efetivamente os condicionantes da realidade objetiva (SOUZA, 2019). Nesse cenário de progressão expandida das incertezas manipuladas, a objetividade jornalística, entendida como a capacidade do repórter de expressar a um público determinada realidade, volta à tona como problemática fértil dos estudos de jornalismo, tópico fundamental para a própria sobrevivência da práxis noticiosa³

Uma das inegáveis contribuições de Adelmo Genro Filho (2012) para a compreensão do jornalismo está em sua descrição dessa prática como uma forma social de conhecimento. Isso significa que essa nova modalidade, inaugurada com a ascensão do modelo industrial capitalista de produção de fatos, trouxe como diferencial um acesso prioritário aos aspectos singulares da realidade. Questionando tanto o positivismo, que prega o acesso puro aos fatos objetivos, quanto o ideologismo, que marca a impossibilidade de separação entre jornalismo e ação política, Genro Filho elabora uma rica compreensão da objetividade jornalística, algo pouco compreendido pelos pesquisadores brasileiros, que, como aponta Pontes (2015), desconhecem a articulação ontológica lukacsiana que serve de baliza para o entendimento da real contribuição do marxismo para as teorias do jornalismo.

Este artigo busca apresentar, nesse sentido, a problemática do conhecimento da realidade pela via da ontologia marxiana e demarcar, em tempos de hegemonia do pensamento irracionalista (NETTO, 2010), a importância da razão dialética na produção noticiosa. Essa abordagem nos permite resgatar a relevância do jornalismo para além dos sintomas de sua possível irrelevância diante do capitalismo comunicacional das plataformas digitais - novo ambiente de sua reprodução (MOROZOV, 2018). A opção pela ontologia "implica a necessidade de investigar as concepções que fundam nossas ideias e as práticas que elas facultam” (DUAYER; SIQUEIRA; ESCURRA, 2013, p. 18). Acreditamos que o cerne dos problemas em torno tanto da rejeição quanto da incompreensão em torno da questão do conhecimento do real pelo jornalismo passa

3 Sobre a temática, pelo ângulo das teorias do jornalismo, podemos citar os estudos de Shudson (2010), Guerra (1998), Demeneck (2009), Tuchmann (2016) e Henriques (2014). 
pela apreensão da relação dialética entre sujeito e objeto no palco de uma base histórico-social.

Assim, na primeira parte demonstraremos os limites de algumas das principais compreensões epistemológicas de objetividade (pautadas em correntes ligadas, em certo sentido, ao neopositivismo, à fenomenologia e ao pragmatismo). Depois, com base na crítica dessas expressões, mostraremos como o padrão marxiano altera o entendimento sobre a concreticidade e como ele problematiza a relação entre o sujeito e a realidade objetiva, demonstrando seu caráter dialético de conhecimento transformador. Por fim, apresentaremos a relevância da razão dialética e a centralidade da objetividade na produção de conhecimento, apontando o potencial do jornalismo crítico como antídoto do irracionalismo predominante na subjetividade mediada pelas tecnologias de informação que eclodem no cerne do sistema sociometabólico do capital (MÉSZÁROS, 2002). Para tanto, essa pesquisa de natureza teórico-conceitual assume o entendimento, com o resgate da perspectiva de Genro Filho (2012), de que a forma social de apropriação da realidade a que chamamos de jornalismo é indispensável para a consumação da liberdade humana e do cultivo de uma vida plena de sentidos.

\section{Realidade objetiva e estudos de jornalismo}

Na maior parte da bibliografia disponível sobre a questão da objetividade é fácil perceber a predominância de uma visão que padece de dois erros principais. Ora nega-se a possibilidade de uma realidade externa ao sujeito, ora afirma-se o império da subjetividade como determinante do conhecimento. Em ambas as situações há uma incompreensão da unidade dialética entre sujeito e objeto. Por outro lado, a "ideologia da objetividade” (GENRO FILHO, 2012) - utilizada pelos próprios profissionais e reelaborada pelo checadores de fatos - trata a realidade como um conjunto de coisas "irretocáveis", confundindo a objetividade com uma pseudoneutralidade política. O resultado é a afirmação do horizonte burguês como a única realidade social possível, cristalizando a aparência reificada da realidade como objetividade. Muitos críticos 
acadêmicos aderem à impossibilidade do conhecimento sobre o real, trabalhando pela semiologização da realidade, que seria impossível conhecer o mundo objetivo.

São razões muito distintas que levam os homens que vivem em nosso tempo a rejeitar a questão da realidade no pensamento e na vida. Tais razões residem em parte numa satisfação com o caráter manipulado de todas as manifestações da vida, em parte numa recusa a essa manipulação; contudo, uma recusa que, no íntimo, está profundamente convicta da inutilidade de libertar-se do estranhamento e que, por isso, busca e encontra justamente nessa falta de perspectiva da própria sublevação uma autoafirmação interior (LUKÁCS, 2012, p. 100).

A crítica ao realismo ingênuo (GOMES, 2009) tende a desconhecer os debates em torno da categoria de realismo no marxismo, o que pode erroneamente ampliar uma genuína crítica ao positivismo até a teoria do reflexo de base leninista. O espelhamento espiritual da realidade, segundo Lukács (2012), jamais significou reflexo fotográfico do real, mas expressão mental de um ser social cuja gênese e transformação se dão em relação dialética com o mundo material. Há uma relativa autonomia do sujeito cognoscente na compreensão da objetividade e também de sua transformação, porém a ontologia marxiana não "perde de vista que a realidade permanece com suas legalidades próprias, que fazem parte da atividade desempenhada, como também de outras realizadas" (PONTES, 2015, p. 268).

Como diz Kosik (2002, p. 32-33), “a consciência humana é 'reflexo' e ao mesmo tempo 'projeção'; registra e constrói, toma nota e planeja, reflete e antecipa; é ao mesmo tempo receptiva e ativa". As categorias do pensamento humano surgem na esfera subjetiva ao mesmo tempo como "produtos e instrumentos da dominação ideal e prática da realidade, paralelamente ao desenvolvimento peculiar dessa mesma realidade (...)" (LUKÁCS, 2012, p. 247). O conhecimento na tradição marxista é a marcha em direção à essência dos fenômenos, em que a abstração mental homogeneíza a heterogeneidade da realidade existente. O ser social, desta feita, é produto da realidade histórica, mas também produtor dela. 
(...) um dos traços específicos do ser social é precisamente o fato de que a consciência não é simplesmente consciência de algo que, no plano ontológico, resta inteiramente indiferente ao fato de ser conhecido; ao contrário, a presença ou a ausência da consciência, sua correção ou falsidade, são parte integrante do próprio ser, ou seja, a consciência não é aqui - em sentido ontológico - mero epifenômeno, independente de quanto seu papel concreto em cada caso singular seja relevante ou irrelevante (LUKÁCS, 2012, p. 241).

Já a adoção crítica do perspectivismo por Gomes (2009), por outro lado, não fundamenta as bases materiais das elucubrações ideais, fazendo com que as dimensões concretas da luta de classes fiquem nubladas. Ora, as particularidades sociais dos agrupamentos humanos possuem lastro objetivo no modo de produção e mesmo as diferenças culturais fazem parte da estrutura concreta de reprodução social, como já atestava o materialismo cultural de Williams (1979). Os tipos ideais de estratificação social que sustentam as ideias de perspectivas e comunidades de interpretação poderiam até auxiliar uma compreensão crítica da sociabilidade humana, mas sem a dimensão de classe, os interesses dados pela busca de respostas recaem em formas idealistas, posto que não há base social realista capaz de sustentar o desnudamento dos interesses em conflito.

Percebe-se que, como aponta Kosik (2002), "toda teoria do conhecimento se apoia, implícita ou explicitamente, sobre uma determinada teoria da realidade e pressupõe uma determinada concepção da realidade mesma” (p. 33). Há por trás das explicações em torno da possibilidade ou não da objetividade jornalística uma figuração de mundo que percorre, nesse sentido, uma expressão não só de visões ideológicas que respondem aos problemas em torno da questão, mas também uma posição em torno da sociedade em que vivemos. Recuperar a ontologia de Marx significa realizar uma crítica das formações reais que estruturam a sociedade como um modo sistêmico de vida norteado pela reprodução ampliada do capital. Assim, a crítica dialética deve apresentar novas figurações de mundo, no interior dos processos de transformação social. 
Em texto muito influente, Sponholz (2009) defende a objetividade, mas não assume em seu arcabouço conceitual, bastante debitário de Karl Popper, a questão das bases ontológicas do ser social, recaindo em uma defesa metodológica e de prescrições instrumentais logicizantes ${ }^{4}$ para o trabalho jornalístico. É importante frisar, com Mészáros (2004), que nenhuma metodologia é neutra, estando delimitada pelos condicionantes históricos e ideológicos e da base econômica de reprodução social. Contudo, ao calibrar os instrumentos de apuração, com imposições metodológicas de aferição da objetividade, Sponholz (2009) levanta o problema da práxis noticiosa, mas que sem uma abordagem crítica e posicionada pode confundir-se com uma práxis utilitária (KOSIK, 2002) incapaz de avançar na desreificação dos aspectos fenomênicos. Isso porque os instrumentos de aferição dos fatos objetivos, sem uma abordagem dialética apropriada, são incapazes de compreender a "coisa em si" que, no mundo dos homens, é produto da própria ação humana. A dialética é o caminho da reprodução intelectual da realidade, ou melhor, é "o método do desenvolvimento e da explicitação dos fenômenos culturais partindo da atividade prática objetiva do homem histórico" (KOSIK, 2002, p. 39).

A manipulação da sociedade capitalista apresenta uma aparência fenomênica da realidade que, para correntes expressivas do pensamento contemporâneo, são elevadas à própria realidade. Assim, mesmo quando expressam um interesse genuíno em conhecer os fenômenos, tornam-se presas do seu caráter fetichista aparente. Lukács critica Nietzsche e Bergson por apresentarem em suas reflexões em torno do conhecimento uma subjetividade que “(...) não está em condições de encontrar na sua própria realidade um lugar para exprimir-se, muito embora esteja - já em sua antitecidade - indissocialmente ligada ao mundo manipulado" (2012, p. 43).

4 Netto (2011) diz que os instrumentos e técnicas de aferição dos fatos podem sempre ser variados e são os meios que permitem ao sujeito conhecer o material investigado; contudo, os resultados dessa investigação são interpretados no horizonte das categorias dinâmicas de totalidade, mediação e contradição. 
Correntes pragmatistas e neopositivistas substituem o conhecimento da realidade pela manipulação formalista dos objetos que lhe são úteis imediatamente e convergem para uma tendência geral que pretende encerrar a possibilidade de fundamentar critérios objetivos de verdade. Para Lukács (2012), a atitude de pensadores que buscam atualizar as reflexões do campo gnosiológico buscando soluções dentro da conjuntura da nova época expressam uma atitude social que reconhece “o irresistível avanço da manipulação no capitalismo contemporâneo como inelutável, como 'destino', mas procuram ostentar uma resistência espiritual às suas consequências ideológicas espontâneas, imediatas" (p. 75). Ao não perceberem saídas para o caráter reificador do modo de produção capitalista e sua delimitação para as ações da vida cotidiana, o máximo que autores que negam a realidade social conseguem é lhe apresentar um protesto impotente. Criticando a tentativa de Heidegger e Scheler de fundar uma ontologia com base no método fenomenológico, o filósofo marxista aponta os limites em considerar somente o ser humano e suas relações sociais imediatas, o que alça ao plano ontológico a "condição universalmente manipulada da sociedade na era do capitalismo altamente desenvolvido” (LUKÁCS, 2012, p. 84). Pois se os fenômenos são aquilo que se mostra em si mesmo, a aparência da realidade imediatamente percebida, que é tipicamente condicionada pelo tempo, torna-se fundamento supratemporal da vida humana. Assim, o risco é demarcar a perceptível essência estranhada do ser em algo irrevogável, sedimentando como característica definitiva as contingências delimitadoras da subjetividade em um modo de produção e reprodução espiritual historicamente constituído.

A apreensão do senso comum, que corresponde à experiência cotidiana dos indivíduos, é dada pela significação meramente "funcional" no universo social vivido. Logo, em termos epistemológicos, a base na qual o fato será assentado e contextualizado tende a reproduzir de maneira latente a universalidade social tal como é vivida imediatamente. Não é por outro motivo que a ideologia das classes dominantes é normalmente hegemônica e o senso comum tende a decodificar os fatos numa perspectiva conservadora (GENRO FILHO, 2012, p. 198). 
Do contrário, o marxismo entende que o pensamento não se estrutura como uma gnosiologia, mas como ontologia. "Isto porque ele compreende que as questões relativas ao conhecimento só podem ser resolvidas após a elaboração de uma teoria geral do ser social" (TONET, 2013, p. 70). A categoria de práxis aparece como um determinante ontológico da relação entre subjetividade e objetividade, regida pela realidade concreta em todas as atividades humanas.

Ora, se o conhecimento é apenas uma das dimensões da totalidade que é o ser social só poderão ser apreendidas na medida em que se conhecerem as determinações mais gerais e essenciais deste ser e na medida em que se identificar o lugar que o conhecimento ocupa na produção e reprodução do ser social como totalidade, ou seja, na práxis social (TONET, 2013, p. 74).

É dessa consideração que eclodem questões como a possibilidade do conhecimento, o que seria o objeto, o sujeito, bem como a verdade. Para isso, na linha de pensamento elaborada por Marx em sua larga obra e reelaborada por Lukács em sua Ontologia, de fato a práxis é a atividade mediadora que conjuga momentos subjetivos e objetivos na definição da realidade social. Consciência e realidade objetiva são dois momentos de igual estatuto ontológico. Para Tonet (2013), o resgate marxiano da realidade objetiva exige uma reelaboração de seu sentido, levando-a em direção de sua dimensão histórico-social. Todavia, repensar a questão da objetividade significa também um reexame da subjetividade, para além de seu superdimensionamento dado por epistemologias pós-modernas e fenomenológicas. Uma teoria da subjetividade jamais pode isolá-la da trama da totalidade concreta do ser social.

A relação sujeito-objeto e a separação daí resultante são dois momentos que implicam a emergência da compreensão da realidade exterior na forma de conceito e a expressão de tal realidade por meio da linguagem. Assim, fica configurado, a partir das condições ontológicas da gênese do trabalho, o fenômeno exclusivamente humano de captura da realidade como possessão espiritual. Esse fenômeno está na raiz do processo 
de conhecimento, cujo aprimoramento continuado conduz à gênese da ciência (DUAYER; SIQUEIRA; ESCURRA, 2013, p. 21).

A conexão insuperável do conhecimento e da prática social é uma contribuição ontológica do marxismo para os estudos do jornalismo, visto que demarca a tarefa de autoconstrução humana como permeada pela práxis do processo de investigação do real. Assim, a própria realidade é o "resultado da síntese entre consciência (momento subjetivo) e realidade (momento objetivo), síntese essa realizada pela prática social" (TONET, 2013, p. 105). Abre-se no padrão marxiano a potencialidade de conhecer não só a aparência, mas também a essência. Contrariamente às tendências hegemônicas do pensamento contemporâneo, que rejeitam a essência, em Marx o conhecimento busca sua verdade para além dos fenômenos imediatamente colocados à primeira vista do contato com o real. O fetiche e o estranhamento como expoentes da sociedade do capital embotam na carapaça da realidade objetiva uma errônea pseudoconcreticidade (KOSIK, 2002) que, presa na práxis utilitária, impede o movimento do ser humano como sujeito de transformações sociais. "Fatos, dados e acontecimentos são sempre resultados condensados de relações e práticas sociais e históricas determinadas. Por isso mesmo, essas relações e práticas sociais históricas têm que ser resgatadas para que se possa compreender os sentidos delas" (TONET, 2013, p. 118). Fundamental nessa investigação é o tratamento da razão dialética, abstração mental e produção simbólica que espelha, no próprio processo de construção da realidade, o mapeamento da objetividade.

O processo do conhecimento é a busca das determinações e de suas relações a fim de que se possa fazer a apreensão do concreto no pensamento. O conhecimento é tanto mais verdadeiro quanto mais estiver saturado de determinações e mediações e, por essa razão, é sempre, apesar de verdadeiro, incompleto (HUNGARO, 2014, p. 72).

Ao assumir a noção de totalidade como um complexo de complexos, Lukács (2012) reconhece que todo conhecimento deve buscar como ponto de partida a própria realidade, abstratamente espelhada na mente, 
e que suas categorias e conexões reveladas possuem caráter ontológico e não lógico. "Todo fato deve ser visto como parte de um complexo dinâmico em interação com outros complexos, como algo que é determinado, tanto interna como externamente, por múltiplas leis" (p. 338). Para Kosik (2002), se o processo de conhecimento não foi capaz de eliminar a pseudoconcreticidade, transpondo a aparência fenomênica da realidade no sentido de acessar a autêntica objetividade histórica, ele se torna escravo do fetiche e da reificação, cujo produto é a má totalidade. A busca pela concreticidade alude ao conhecimento do caráter histórico do fenômeno, bem como sua função objetiva no seio do corpo social.

A práxis é o critério decisivo de todo conhecimento correto porque ela cumpre objetivamente o papel de enredar a dinâmica e os movimentos do ser social em sua relação insuperável com a materialidade econômica e social de sua época. A práxis “é a revelação do segredo do homem como ser ontocriativo, como ser que cria a realidade (humano-social) e que, portanto, compreende a realidade (humana e não humana, a realidade em sua totalidade)" (KOSIK, 2002, p. 222). Ela se manifesta tanto na atividade objetiva do homem, que dá sentido humano à natureza, como na formação da subjetividade, cujos afetos e sentimentos existenciais são parte da busca pela liberdade.

\section{Conhecimento, objetividade e classes}

Adelmo Genro Filho (2012) aponta que a realidade objetiva oferece inúmeras possibilidades de significações e aponta que os sentidos são produzidos na dialética entre os objetos em si mesmos e na relação sujeito-objeto. As notícias são recortes do fluxo dos processos objetivos da realidade que são elaborados atendendo a determinações tanto objetivas quanto subjetivas. Ser e objetividade fazem parte de um mesmo complexo de múltiplas determinações. Assim, há certamente espaço para a incidência da ideologia e das decisões individuais, o que não altera o processo de conhecimento. 
Nessa medida, é inevitável que os fatos sejam, em si mesmos, uma escolha. Mas, para evitar o subjetivismo e o relativismo, é importante agregar que essa escolha está delimitada pela matéria objetiva, ou seja, por uma substância histórica e socialmente constituída, independentemente dos enfoques subjetivos e ideológicos em jogo (GENRO FILHO, 2012, p. 197).

Para o teórico brasileiro do jornalismo, a realidade social enquanto totalidade concreta resulta da processualidade de transformação das necessidades em liberdade por meio do trabalho. Mesmo sem conhecer a fundo a categoria de pôr teleológico em Lukács (2012 e 2013), Genro Filho (2012) intui uma percepção semelhante do papel do sujeito na construção da totalidade concreta, percebendo que sujeito e objeto, em sua unidade e diferença, articulam-se dialeticamente na autoconstrução da história humana.

Outra tese que Genro Filho (2012) deriva das impostações ontológicas marxianas é que o conhecimento é infinito, visto que a totalidade é dinâmica e sempre viva, resultante de totalizações constantes. Isso alude ao fato de que reconhecer a totalidade, como bem aponta Kosik (2002), não pode ser entendido como a busca de uma verdade totalizante abarcadora de todos complexos sistêmicos, mas o reconhecimento de uma estrutura dinâmica, que relaciona as partes com o todo e o todo com as partes. Essa totalidade se movimenta com base nas contradições entre os complexos, cujo ritmo e condições são dados pelas mediações entre os distintos níveis da estrutura de cada totalidade (NETTO, 2011).

O conhecimento dos objetos contém a subjetividade como dimensão inseparável da realidade, sendo sempre comprometido politicamente, visto que se posiciona em relação às possibilidades e devires da autoconstituição do ser social. "Pelo conhecimento da práxis, a objetividade pode ser revelada em seu movimento, como tendências e possibilidades concretas. A subjetividade, então, reconhece-se a si mesma e toma consciência das suas limitações e potencialidades" (GENRO FILHO, p. 96, 2012). O homem é parte desse mundo objetivo, ou seja, produz o objeto e é produzido por ele. A centralidade da objetividade implica, portanto, 
reconhecer que corpo e espírito são partes da mesma realidade social. Assim, há um claro papel da subjetividade e do interesse na compreensão do mundo, e jornalistas e seus interesses são fundamentais para o ato de conhecimento, pois a subjetividade não é uma doença ou obstáculo a ser superado pela objetividade, mas condição da própria possibilidade da verdade. Esta tem como instância de verificação a prática social e histórica.

Isto é, toda a atividade humana está determinada por certo gradiente de intencionalidade - a consciência é responsável tanto pela reprodução conceitual (a abstração que coloca no centro da atividade, ao mesmo tempo, a conexão entre meios e fins e também a ideação prévia a respeito do objeto) como pela produção espiritual, esta resultante da atividade mais complexa do ser humano, na esfera de criação já distanciada da relação imediata entre homem e natureza, mas cuja complexificação só tornou-se possível graças à sociabilização primeira do elemento natural (RANIERI, 2011, p. 130).

A posição de classe é inescapável dos processos de conhecimento como o jornalismo e a ideologia, entendida por Mészáros (2004) como a forma por meio da qual os homens tornam-se conscientes dos conflitos e nele se colocam em luta. Como diz Žižek, não devemos realizar uma "análise neutra, mas sim engajada e extremamente "parcial", pois a verdade é parcial, só acessível quando se adota um dos lados, mas nem por isso menos universal" (2011, p. 18). Só que reconhecer isso não pode ser confundido com a instrumentalização do jornalismo como aparelho de classe, servindo às demandas estratégicas de uma organização determinada (partido, movimento etc.). Genro Filho (2012) identifica os pressupostos ideológicos e ontológicos como condicionantes da produção noticiosa, que delimitam a ótica pela qual os fatos são investigados, o que permite tanto a afirmação do senso comum da irracionalidade que permeia o capitalismo manipulado como a crítica contra as formas fetichizadas coladas aos fenômenos. Em se tratando do conhecimento científico, o marxismo reconhece a impossibilidade da neutralidade e imparcialidade na investigação do real, mas demarca na opção pela 
classe trabalhadora um lugar capaz de avançar na revelação da essência por trás dos fenômenos.

Quais os pressupostos, vinculados a que concepção de mundo, que demarcam cada perspectiva? A quem interessa conhecer a realidade e em que nível? Fica claro, desse modo, que a tomada de partido não é, necessariamente, um obstáculo para a compreensão científica da realidade. Pelo contrário, desde que assumida a perspectiva da classe que, naquele momento histórico, fundamenta o padrão cognitivo mais elevado possível, a tomada de partido se revela uma condição positiva e imprescindível para a elaboração do conhecimento científico (TONET, 2012, p. 111).

Como já dissemos anteriormente, a relação entre sujeito e objeto na visão do materialismo histórico não é de externalidade, pois o sujeito está inserido no objeto, e disso deduzimos que o conhecimento produzido pelo jornalismo jamais é neutro. Contudo, não se deve confundir a neutralidade com a temática da objetividade. A condição da própria investigação do real é a atividade do sujeito cognoscente (ser social), pois pela sua posição é possível extrair as determinações dos fatos (o singular produzido pelas notícias). É evidente que dessa perspectiva de classe não se pode retirar o campo das escolhas (éticas) em torno da fidelidade ao objeto, pois o sujeito é ativo no espelhamento do real. A exatidão para com os resultados de uma apuração, desta feita, não pode ser nublada para sustentar uma verdade ideológica precedente. A perspectiva de classe, sem a atuação do sujeito ativo, não garante a efetividade do saber produzido. Até mesmo porque, para os sujeitos críticos à ordem burguesa, a objetividade do conhecimento só se pode confirmar na prática enquanto critério de aferição. E uma teoria errada leva a uma prática equivocada. A capacidade intelectual do jornalista, não obstante, exige uma operação sofisticada de percepção das contradições expostas na totalidade. O marxismo fornece pistas desta conduta, visto que

(...) em toda verificação de fatos singulares, em toda reprodução ideal de uma conexão concreta, tem sempre em vista a totalidade do ser social e, com base nela, sopesa a realidade e o significado de cada fenômeno singular; uma análise ontológica-filosófica da realidade em si que jamais 
vaga, mediante a autonomização de suas abstrações, acima dos fenômenos operados, mas, ao contrário, justamente por isso, conquistou para si crítica e autocriticamente o estágio máximo da consciência, para poder captar todo ente na plena concretude da forma de ser que lhe é própria, que é específica precisamente dele (LUKÁCS, 2012, p. 296).

Com base nessa articulação, Genro Filho (2012) mira no singular enquanto peculiaridade da práxis noticiosa e aponta que tanto o particular quanto o universal estão apresentados ou sugeridos, o que decorre da compreensão (também metodológica desse conhecimento) do singular como ponto de chegada da investigação crítico-dialética da realidade social. O jornalismo, desta feita, pode ser compreendido como "uma práxis que tem fundamentação objetiva e subjetiva tanto em relação ao conteúdo com o qual trabalha (os fatos sociais) como pela forma de apreensão e transformação desse conteúdo (o trabalho dos jornalistas em transformar fatos sociais em fatos jornalísticos)" (PONTES, 2015, p. 363).

Assim, enfeixam-se na articulação ontológica do jornalismo defendida pelo materialismo histórico dialético motivos suficientes para o resgate da noção de objetividade no jornalismo para além de suas incrustações neopositivistas, fenomenológicas e pragmatistas, que, de maneiras distintas, cimentam a essência manipulada do capitalismo comunicacional (DEAN, 2010) do século XXI.

\section{Considerações finais}

A narrativa produzida historicamente pelo jornalismo informativo apresenta uma perspectiva de abertura de sentido (PONTES, 2015) que lhe é peculiar. Ela também possibilita a busca de um conhecimento sobre a realidade histórica em sua dimensão singular que permanece não só atual como necessária. As características que elegem essa forma de conhecimento como uma potência mesmo no cenário de crise do capital e o irracionalismo predominante no território digital perpassam a relação que essa práxis tem com a vida cotidiana, local central das mudanças 
qualitativas necessárias a outra forma de sociabilidade, visto que, sem alterar substantivamente os pores teleológicos das classes subalternas, nenhum outro mundo será construído.

Todavia, um dos saberes necessários a essa prática jornalística é a crítica ontológica, inevitavelmente munida de uma postura ideológica que se conecte à busca pela concreticidade. Um jornalismo, na esteira de Adelmo Genro Filho (2012), pode esclarecer caminhos e expressar uma visão mais ampla dos aspectos fundamentais da estruturação da realidade, tendo como porta de acesso o singular. Segundo a impostação de Lukács, o objeto da ontologia marxista, diferentemente da ontologia clássica e subsequente, "é o que existe realmente: a tarefa é a de investigar o ente com a preocupação de compreender o seu ser e encontrar os diversos graus e as diversas conexões em seu interior" (2014, p. 27).

$\mathrm{O}$ que podemos apontar, para além de uma objetividade neutralizada, alvo das críticas de autores clássicos dos estudos de jornalismo, é que a perspectiva ontológica nos dá bases para um novo patamar de conhecimento, isso ao aglutinar o contato com a realidade a uma postura afinada com a ótica das classes subalternas. O impulso coletivo pela compreensão da realidade social deve ser o horizonte de uma prática jornalística crítica, fundamental para se conhecer o mundo em que vivemos. Isso porque, no cenário da luta de classes, cabe a quem desenvolve sua prática social transformadora a exatidão do território em que precisa transitar.

Entendemos a razão crítica como uma vertente dialética de esclarecimento, embate racional, e, mais do que isso, elevação do potencial do jornalismo como reconhecimento vital dos aspectos singulares da realidade, que podem determinar e delimitar o horizonte e a conscientização dos sujeitos em torno de um projeto de luta social. Para além do irracionalismo do senso comum contemporâneo, a razão dialética aplicada ao jornalismo torna-se um projeto consistente de busca de alterações nas bases sociais que sustentam o metabolismo reinante. $\mathrm{O}$ desafio para esse resgate da realidade objetiva no conhecimento proporcionado pelo jornalismo está na hegemonia cada dia mais intensa 
dos estranhamentos cotidianos potencializados pelo ambiente digital. A superação desses processos de ditadura fetichista das estruturas de sentimento não pode nunca ser vista como tarefa unicamente gnosiológica, pois, sem alterações ontológicas no mundo da vida material, portanto sem a práxis coletiva dos sujeitos sociais, o irracionalismo tende a mascarar as possibilidades de avanço crítico na consciência dos indivíduos.

O jornalismo não pode ser descartado simplesmente pelo uso que tem sido dado a ele nos últimos tempos, colocando como seu horizonte a postura viciosa e antiética das boatarias em território digital. A bandeira de uma prática jornalística crítica e emancipatória precisa ser o eixo principal dos teóricos do jornalismo e daqueles que se engajam em diversos arranjos diferenciados, seja em coletivos, cooperativas, movimentos sociais ou dos virtuosos jornalistas críticos que ainda permanecem nas cadeiras da imprensa convencional. Para isso, é fundamental reconhecer de forma bastante precisa que há um mundo a conhecer e transformar.

\section{Referências}

CASTELLS, M. A sociedade em rede. São Paulo: Paz e Terra, 2007.

DEAN, J. Blog Theory. Cambridge: Polity, 2010.

DEMENECK, B. Objetividade Jornalística: o debate contemporâneo do conceito. 2009. 133 f. (Mestrado em Jornalismo) - Centro de Comunicação e Informação. Universidade Federal de Santa Catarina, Florianópolis, Santa Catarina. 2009.

DUAYER, M.; SIQUEIRA, A.; ESCURRA, M. F. A ontologia de Lukács e a restauração da crítica ontológica em Marx. R. Katál., Florianópolis, v. 16, n. 1, p. 17-25, jan./jun. 2013.

EAGLETON, T. As ilusões do pós-modernismo. Rio de Janeiro: Zahar, 1996.

FREDERICO, C.; TEIXEIRA, F. Marx no Século XXI. São Paulo: Cortez, 2008.

FUCHS, C. Em direção a uma problemática marxista de estudos sobre a internet. Crítica Marxista, Campinas, n. 43, p. 67-93, jul./dez. 2016.

GENRO FILHO, A. O segredo da pirâmide - para uma teoria marxista do jornalismo. Florianópolis: Insular, 2012.

GOMES, W. Jornalismo, fatos e interesses: ensaios de teoria do jornalismo. Florianópolis: Insular, 2009.

GUERRA, Josenildo. A objetividade no jornalismo. 1998. 186 p. Dissertação (Mestrado em Comunicação) - Faculdade de Comunicação, Universidade Federal da Bahia, Salvador. 1998. 
HENRIQUES, R. P. Linguagem, Verdade e Conhecimento. Vitória, ES: EDUFES, 2014.

HUNGARO, E. M. A questão do método na teoria social de Marx. In: CUNHA, C.; SOUSA, J. V.; SILVA, M. A. O método dialético na pesquisa em educação. Campinas: Autores Associados, 2014. p. 15-78.

KOSIK, K. Dialética do concreto. Rio de Janeiro: Paz e Terra, 2002.

LUKÁCS, G. Conversando com Lukács: entrevistas a Leo Kofler, Wolfgang Abendroth e Hans Heinz Holz. São Paulo: Instituto Lukács, 2014.

LUKÁCS, G. Marx e Engels como historiadores da literatura. São Paulo: Boitempo, 2016.

LUKÁCS, G. Para uma ontologia do ser social I. São Paulo: Boitempo Editorial, 2012.

MÉSZÁROS, I. O poder da ideologia. São Paulo: Boitempo Editorial, 2004.

MORETZSOHN, S. "Uma legião de imbecis": hiperinformação, alienação e o fetichismo da tecnologia libertária. Liinc em Revista, Rio de Janeiro, v. 13, n. 2, p. 294-306, ago./dez. 2017.

MOROZOV, E. Big Tech: a ascensão dos dados e a morte da política. São Paulo: Ubu Editora, 2018.

NETTO, J. P. Introdução ao estudo do método de Marx. São Paulo: Expressão Popular, 2011.

NETTO, J. P. Posfácio. In: COUTINHO, C. N. O estruturalismo e a Miséria da Razão. 2. ed. São Paulo: Expressão Popular, 2010.

PONTES, F. Adelmo Genro Filho e a Teoria do Jornalismo. Florianópolis: Insular, 2015. RANIERI, J. Trabalho e Dialética: Hegel, Marx e a teoria social do devir. São Paulo: Editora Boitempo, 2011.

SCHUDSON, M. Descobrindo a notícia: uma história social dos jornais nos Estados Unidos. Petrópolis, RJ: Vozes, 2010.

SPONHOLZ, L. Jornalismo, Conhecimento e objetividade: além do espelho e das construções. Florianópolis: Insular, 2009.

SOUZA, R. B. R de. "Fake news", pós-verdade e sociedade do capital: o irracionalismo como motor da desinformação jornalística. Revista FAMECOS, v. 26, n. 3, p. e33105, 27 dez. 2019. Disponível em: https://revistaseletronicas.pucrs.br/ojs/index.php/ revistafamecos/article/view/33105

TONET, I. Método científico: uma abordagem ontológica. São Paulo: Instituto Lukács, 2013.

TUCHMAN, G. A objetividade como ritual estratégico: uma análise das noções de objetividade dos jornalistas. In: TRAQUINA, N. (Org.). Jornalismo: questões, teorias e "estórias". Florianópolis: Insular, 2016. p. 111-131.

WILLIAMS, R. Marxismo e Literatura. Rio de Janeiro: Zahar, 1979.

ŽIŽEK, S. (Org.). Primeiro como farsa, depois como tragédia. São Paulo: Boitempo, 2011 . 


\section{Sobre 0 autor}

Rafael Bellan Rodrigues de Souza - Professor do Programa de Pós-Graduação em Comunicação e Territorialidades da Universidade Federal do Espírito Santo (Ufes). Jornalista, mestre em Comunicação pela Unesp (Bauru), doutor em Ciências Sociais pela Unesp (Araraquara) com pós-doutorado pela ECA-USP.

Data de submissão: 28/10/2019

Data de aceite: $03 / 11 / 2020$ 